\title{
Does the type of treatment have an influence on utility values in a glaucoma population?
}

\author{
This article was published in the following Dove Press journal: \\ Clinical Ophthalmology \\ 7 September 2015 \\ Number of times this article has been viewed
}

\section{Ricardo Augusto Paletta \\ Guedes ${ }^{1-3}$ \\ Vanessa Maria Paletta \\ Guedes ${ }^{1-3}$ \\ Sirley Maria Freitas ${ }^{2}$ \\ Alfredo Chaoubah'}

'Federal University of Juiz de Fora, 2Paletta Guedes Ophthalmological Center, ${ }^{3}$ Santa Casa de Misericórdia Hospital, Juiz de Fora, MG, Brazil

Correspondence: Ricardo Augusto Paletta Guedes

Av Rio Branco 2644/I00I, Centro, Juiz de Fora, MG 360I0-905, Brazil

Tel/fax +553232/3 1927

Email palettaguedes@yahoo.com
Purpose: To assess the impact of glaucoma therapy on utility values in a glaucoma population.

Methods: A cross-sectional study of consecutive glaucoma patients was conducted. Utility values were obtained using the time trade-off method. Visual function variables (visual acuity and mean deviation in the better eye) and sociodemographic and clinical characteristics (age, sex, race, educational level, type of glaucoma, current and past glaucoma treatments, and comorbidities) were also obtained for statistical analysis. We divided the patients into three groups: medical treatment (group 1), surgical treatment (group 2), and mixed surgical and medical treatment (group 3).

Results: Mean age of the study population $(n=225)$ was 65.7 years. After controlling for glaucoma stage (early, moderate, and advanced), the difference among the groups in mean utility values was not statistically significant. Number of medications per patient, type of medication, or type of surgical technique did not have an impact on the utility values.

Conclusion: Our findings suggest that the type of therapy did not affect the utility values in a glaucoma population.

Keywords: quality of life, glaucoma treatment, glaucoma surgery

\section{Introduction}

Glaucoma is a chronic disease which affects many aspects of an individual. ${ }^{1}$ At the end-stage disease, it can lead to irreversible blindness, but, even in earlier stages, it also has a major impact on a person's perceived quality of life (QoL) and on their ability to perform daily activities. ${ }^{1-4}$

There are many possible causes of the impact of glaucoma on a patient's QoL: functional loss (visual field deterioration); worries and anxiety due to diagnosis; inconvenience; side effects; and cost of treatment. ${ }^{5}$

The impact of different glaucoma therapies on QoL has been the subject of investigation by some authors. The Collaborative Initial Glaucoma Treatment Study (CIGTS), which randomized newly diagnosed glaucoma patients to medications versus trabeculectomy, found that surgery-treated patients had a lower QoL in the early period due to some localized symptoms. In both groups, QoL scores were lower right after the diagnosis; however, they became better with time, demonstrating that patients can get used to their disease and its treatment. ${ }^{6}$ Our group found in a cross-sectional study that surgery only affected QoL scores in earlier stages of glaucoma severity. ${ }^{7}$

Utility values are a generic QoL metric of a person's health status and it was developed to allow comparisons among different health states (eg, people affected by different diseases). ${ }^{8-11}$ Utility values range from 0 (death) to 1 (perfect health) and they measure the patient's preference for a health state. It is also used in cost-utility 
evaluations. ${ }^{8,11}$ In these economic evaluations, effectiveness is measured in quality-adjusted life-years, which derives directly from the utility values. Utility values can be different according to the studied population. In a previous study, our group described the utility values for a Brazilian population with glaucoma, using different approaches: time trade-off (TTO) and standard gamble. ${ }^{12}$ It is not known in the literature if the type of treatment has an influence on the utility values in a glaucoma population.

The purpose of this study was to investigate if the utility values are affected by the type of glaucoma therapy (medical or surgical).

\section{Materials and methods}

For this cross-sectional study, we invited consecutive glaucoma patients at a glaucoma referral clinic. Inclusion criteria were: over 18 years old; and under glaucoma treatment for at least 1 year. Exclusion criteria were: refusal to participate in the study; cognitive inability to answer the research questions; lack of data in the chart; having undergone glaucoma surgery during the past 3 months; and combined cataract and glaucoma surgeries. We decided to exclude these combined cataract and glaucoma surgeries because cataract surgery can have an impact on a patient's QoL, thus influencing our results. All study participants signed an informed consent form. The majority of the participants for this study were also present in a previous study by our group. ${ }^{12}$ Both studies are part of much larger research project: Economic Analysis of Glaucoma in Brazil.

Participants were treated anonymously (identified by the record number). All the interviews were conducted by the same researcher (SMF), who was trained specifically for this study and masked to the clinical information. The interviews took place before the consultation to avoid any influence of the medical evaluation on the responses related to QoL. First of all, patients answered questions about their level of education. A caregiver assisted illiterate patients with the interview and with the utility exercise, but the interviewer strongly avoided caregiver influence on the answers by instructing them not to answer the question or to try to explain it to patients. Subsequently, participants/patients responded the questions for obtaining utility values by the method of TTO. Participants were asked two questions: the first one about their expected life expectancy (the number of remaining life-years they expected to live) and the second one about the number of years they were willing to trade in return for perfect health. Utility values were obtained according to the following formula:

$$
\text { Utility value }=1-\frac{\text { Years willing to lose }}{\text { Years expected to live }}
$$

The interviewer instructed the patients not to assign to the years they were willing to lose a higher value than the years they expected to live, in order to avoid the result of a negative utility value (health states perceived as worse than death), as we chose as TTO limits 0 (death) and 1 (perfect health).

We obtained the following clinical variables from the medical records: age, sex, level of education, type of glaucoma, and stage of glaucoma (categorized into three groups: early, moderate, advanced [based on the HodappParrish-Anderson criteria $\left.{ }^{13}\right]$ ). Additionally included was visual acuity, categorized into three groups: $>0.5$ (good vision); from 0.5 to $>0.1$ (low vision); and from 0.1 to no light perception (legal blindness). We also assessed current glaucoma therapy; history of previous glaucoma surgery; systemic comorbidity (diabetes, cardiovascular disease, asthma, cancer); and ocular comorbidity (cataract, corneal diseases, retinal vascular diseases) in the eye with better visual acuity and in the eye with the worse visual acuity.

We divided the patients into three groups:

- group 1: medical treatment (patients receiving medical therapy who had never undergone filtering surgery in either eye);

- group 2: surgical treatment (patients who had undergone glaucoma surgery in both eyes and were not currently using glaucoma medications); and

- group 3: mixed medical and surgical treatment (patients who had undergone glaucoma surgery in either eye and were currently using glaucoma medications).

We tested the variable distributions for normality. Comparisons between variables were done using the chi-square test (categorical) and the ANOVA test (numerical) for those variables with normal distributions. For the utility value comparisons, there was an expected nonnormal distribution, so we used a nonparametric test (Kruskal-Wallis test). We considered a significance level of $95 \%$ and statistical analysis was performed using SPSS 15.0 (SPSS Inc., Chicago, IL, USA).

This study was approved by the ethics committee of the Federal University of Juiz de Fora, Brazil and adhered to the tenets of the Declaration of Helsinki.

\section{Results}

For this study, the participation rate was 80.2\% (227/283). Fifty-six patients met the inclusion and exclusion criteria and were invited but did not want to participate in the study. The main reason was lack of time for answering the questions. We excluded two patients because they were not on any glaucoma treatment. They had not been operated on for glaucoma, nor 
were they on topical medications. They had been operated on for cataract surgery, and intraocular pressure control was achieved after surgery. We decided not to consider the cataract surgery as a glaucoma surgical option, so we did not include these two patients in the study.

Mean age ( \pm standard deviation) of the entire population was $65.76( \pm 15.20)$ years (range: $17-77$ years). Since different age groups can have different views of their disease and QoL and the age range was very broad, we analyzed our results according to the following age ranges: $<40$ years $(n=15)$; from 40 to 59 years $(n=50)$; from 60 to 79 years $(n=120)$; and $>79$ years $(n=40)$. Table 1 shows the clinical characteristics of the 225 participants who comprised the studied population.

Comparisons among the three groups are demonstrated in Table 2. Groups were homogenous according to the

Table I Clinical characteristics of the studied populations $(n=225)$

\begin{tabular}{|c|c|}
\hline Clinical characteristics $(n=225)$ & Number (\%) \\
\hline \multicolumn{2}{|l|}{ Sex } \\
\hline Male & $88(39.1)$ \\
\hline Female & $137(60.9)$ \\
\hline \multicolumn{2}{|l|}{ Race } \\
\hline White & $160(71.1)$ \\
\hline African-American & $39(17.3)$ \\
\hline Mixed $^{a}$ & $26(11.6)$ \\
\hline \multicolumn{2}{|l|}{ Type of glaucoma } \\
\hline POAG & $175(77.8)$ \\
\hline ACG & $29(12.9)$ \\
\hline Other (pigmentary and pseudoexfoliation glaucoma) & $21(9.3)$ \\
\hline \multicolumn{2}{|l|}{ Stage of glaucoma ${ }^{\mathrm{b}}$} \\
\hline Early & $130(57.8)$ \\
\hline Moderate & $32(14.2)$ \\
\hline Advanced & $63(28.0)$ \\
\hline \multicolumn{2}{|l|}{ Visual acuity in the better-seeing eye (decimal) } \\
\hline$>0.5$ & I $74(77.3)$ \\
\hline From 0.5 to $>0.1$ & $44(19.6)$ \\
\hline From 0.1 to no light perception & $7(3.1)$ \\
\hline \multicolumn{2}{|l|}{ Type of treatment } \\
\hline Medical treatment ${ }^{c}$ & $82(36.4)$ \\
\hline Surgical treatment ${ }^{d}$ & $47(20.9)$ \\
\hline Medical and surgical treatment $\mathrm{e}^{\mathrm{e}}$ & $96(42.7)$ \\
\hline \multicolumn{2}{|l|}{ Level of education } \\
\hline Illiteracy & $19(8.4)$ \\
\hline Elementary school & $74(32.9)$ \\
\hline Secondary school & $61(27.1)$ \\
\hline Undergraduate/graduate school & $71(31.6)$ \\
\hline
\end{tabular}

Notes: ancludes mixed blacks/whites and mixed Native Americans/whites. bGlaucoma stage based on the Hodapp-Parrish-Anderson staging system. ${ }^{13}$ Patients receiving medical therapy who had never undergone filtering surgery in either eye. dPatients who had undergone filtering surgery in both eyes and were not current

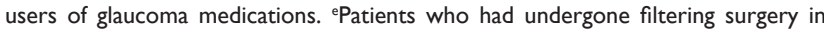
either eye and were current users of glaucoma medications.

Abbreviations: ACG, angle-closure glaucoma; POAG, primary open-angle glaucoma. following variables: age, sex, race, type of glaucoma, and level of education. The mean number of medications was higher in group 3 in comparison to group 1 (2.1 versus 1.8). This difference was statistically significant, but not clinically relevant. Eyes with worse vision (either worse visual acuity or more advanced glaucoma) had an expected higher proportion of glaucoma surgery.

No significant differences among the studied groups were found concerning ocular comorbidity in the better eye ( $P=0.228$, chi-square test) or systemic comorbidity $(P=0.569$, chi-square test).

Mean utility values \pm standard deviation for the age ranges were as follows ( $P=0.447$, Kruskal-Wallis test $):<40$ years: $0.8584 \pm 0.1601 ; 40-59$ years: $0.8249 \pm 0.1844 ; 60-79$ years: $0.8003 \pm 0.2089$; and $>79$ years: $0.8531 \pm 0.2352$.

Glaucoma stage had an impact in utility values as we can see in the results below. Mean utility values \pm standard deviation (95\% confidence interval) for the glaucoma stages were the following $(P=0.002$, Kruskal-Wallis test): early glaucoma: $0.8563 \pm 0.01700(0.8227-0.8900)$; moderate glaucoma: $0.7966 \pm 0.03412(0.7271-0.8662)$; advanced glaucoma: $0.7534 \pm 0.02780(0.6978-0.8090)$.

Glaucoma stage could have had a major impact on the results, so we decided to stratify the studied population according to this variable. Table 3 shows the results of this analysis, where we can see that there was no significant difference among the studied groups when controlled by glaucoma stage. By performing this analysis, we excluded any influence of the choice of the therapy according to the stage of the disease.

The type of glaucoma did not have an impact on the mean utility values. Primary open-angle glaucoma patients had the following mean \pm standard deviation utility value: $0.8135 \pm 0.2053$, while angle-closure glaucoma patients and other types of glaucoma patients presented the following means \pm standard deviations, respectively: 0.8240 \pm 0.2337 and $0.8582 \pm 0.1719$ ( $P=0.451$, Kruskal-Wallis test). Other types of glaucoma included pigmentary and pseudoexfoliation glaucoma.

Approximately $80 \%$ of patients $(65 / 82)$ in group 1 had chronic use of a prostaglandin analog (bimatoprost: $8.5 \%$; latanoprost: $36.6 \%$; travoprost: $34.1 \%)$. Other medications were: beta-blockers: $62.2 \%$ (51/82); alpha-2 agonists: $14.6 \%$ $(12 / 82)$; and topical carbonic anhydrase inhibitors (CAIs): $22.0 \%$ (18/82). Patients in group 3 had use of one or more of the following medications (with their respective proportions): prostaglandin analog: 61.5\% (59/96); beta-blockers: 84.4\% (81/96); alpha-2 agonists: 35.4\% (34/96); topical 
Table 2 Clinical characteristics and comparisons among groups I (medical treatment), 2 (surgical treatment), and 3 (medical and surgical treatment)

\begin{tabular}{|c|c|c|c|c|}
\hline Characteristics & Group I $(\mathbf{N}=\mathbf{8 2})$ & Group $2(\mathrm{~N}=47)$ & Group $3(\mathbf{N}=96)$ & $P$-value \\
\hline Mean age (years) & 66.7 & 66.5 & 64.64 & $0.63 \mathrm{I}^{\mathrm{a}}$ \\
\hline Mean number of medications per patient & 1.8 & NA & 2.1 & $0.030^{\mathrm{a}}$ \\
\hline \multicolumn{5}{|l|}{ Sex } \\
\hline Male & $39.0 \%$ & $40.4 \%$ & $38.5 \%$ & \multirow[t]{2}{*}{$0.977^{b}$} \\
\hline Female & $61.0 \%$ & $59.6 \%$ & $61.5 \%$ & \\
\hline \multicolumn{5}{|l|}{ Race } \\
\hline White & $76.8 \%$ & $68.1 \%$ & $67.7 \%$ & \multirow[t]{3}{*}{$0.156^{\mathrm{b}}$} \\
\hline African-American & $12.2 \%$ & $12.8 \%$ & $24.0 \%$ & \\
\hline Mixed $^{c}$ & $11.0 \%$ & $19.1 \%$ & $8.3 \%$ & \\
\hline \multicolumn{5}{|l|}{ Type of glaucoma } \\
\hline POAG & $85.4 \%$ & $80.9 \%$ & $69.8 \%$ & \multirow[t]{3}{*}{$0.244^{b}$} \\
\hline ACG & $8.5 \%$ & $8.5 \%$ & $18.8 \%$ & \\
\hline Other (pigmentary and pseudoexfoliation glaucoma) & $6.1 \%$ & $10.6 \%$ & $11.4 \%$ & \\
\hline \multicolumn{5}{|l|}{ Stage of glaucoma ${ }^{d}$} \\
\hline Early & $82.9 \%$ & $34.0 \%$ & $47.9 \%$ & \multirow[t]{3}{*}{$<0.00 I^{b}$} \\
\hline Moderate & $8.5 \%$ & $29.8 \%$ & $11.5 \%$ & \\
\hline Advanced & $8.5 \%$ & $36.2 \%$ & $40.7 \%$ & \\
\hline \multicolumn{5}{|l|}{ Visual acuity in the better-seeing eye (decimal) } \\
\hline$>0.5$ & $93.9 \%$ & $76.6 \%$ & $63.5 \%$ & \multirow[t]{3}{*}{$0.002^{b}$} \\
\hline From 0.5 to $>0.1$ & $4.9 \%$ & $21.3 \%$ & $31.3 \%$ & \\
\hline From 0.1 to no light perception & $1.2 \%$ & $2.1 \%$ & $5.1 \%$ & \\
\hline \multicolumn{5}{|l|}{ Level of education } \\
\hline Illiteracy & $4.9 \%$ & $8.5 \%$ & $11.5 \%$ & \multirow[t]{4}{*}{$0.138^{b}$} \\
\hline Elementary school & $23.2 \%$ & $36.2 \%$ & $39.6 \%$ & \\
\hline Secondary school & $32.9 \%$ & $27.7 \%$ & $21.9 \%$ & \\
\hline Undergraduate/graduate school & $39.0 \%$ & $27.6 \%$ & $27.1 \%$ & \\
\hline Utility values (mean \pm standard deviation) & $0.8664 \pm 0.2068$ & $0.8068 \pm 0.02767$ & $0.7846 \pm 0.02267$ & $0.017^{\mathrm{e}}$ \\
\hline
\end{tabular}

CAIs: $29.2 \%$ (28/96); and systemic CAIs: $2.1 \%(2 / 96)$. The proportions of different prostaglandin analogs within group 3 were bimatoprost: $20.8 \%$; latanoprost: $14.6 \%$; and travoprost: $26.0 \%$.

Utility values did not differ according to the number of medications used per patient. Patients using one $(n=74)$, two $(n=56)$, three $(n=30)$, or four $(n=18)$ topical medications had respective mean utility values of $0.8347,0.8257,0.8004$, and 0.7970 ( $P=0.921$, Kruskal-Wallis test). The presence of any given medication in the treatment did not have any influence in the utility values. Patients with use of a beta-blocker $(n=132)$, for instance, had a mean utility value of 0.8074 , and patients without use of one $(n=93)$ had a mean utility value of 0.8356 ( $P=0.312$, Kruskal-Wallis test). The same occurred with all other medication types (prostaglandin analogs: $P=0.268$; alpha-2 agonists: $P=0.912$; topical CAIs: $P=0.903$; systemic CAIs: $P=0.750$ ). We did not find any differences in the mean utility values among the patients using different prostaglandin

Table 3 Utility values in groups I (medical treatment), 2 (surgical treatment), and 3 (medical and surgical treatment), controlled by glaucoma stage

\begin{tabular}{|c|c|c|c|c|c|c|c|}
\hline \multicolumn{8}{|l|}{ Utility values } \\
\hline \multirow[t]{2}{*}{ Glaucoma stage } & \multicolumn{2}{|l|}{ Group I } & \multicolumn{2}{|l|}{ Group 2} & \multicolumn{2}{|l|}{ Group 3} & \multirow[t]{2}{*}{$P$-value } \\
\hline & Mean \pm SD & $95 \% \mathrm{Cl}$ & Mean \pm SD & $95 \% \mathrm{Cl}$ & Mean \pm SD & $95 \% \mathrm{Cl}$ & \\
\hline Early & $0.8704 \pm 0.02223$ & $0.8260-0.9148$ & $0.8569 \pm 0.05431$ & $0.74 I I-0.9726$ & $0.8354 \pm 0.02992$ & $0.775 \mathrm{I}-0.8956$ & $0.64 I$ \\
\hline Moderate & $0.8225 \pm 0.08158$ & $0.6229-1.0221$ & $0.7597 \pm 0.05216$ & $0.6470-0.8723$ & $0.8273 \pm 0.05606$ & $0.7024-0.9522$ & 0.648 \\
\hline Advanced & $0.87|4 \pm 0.0837|$ & $0.6666-1.0763$ & $0.7985 \pm 0.03739$ & $0.7192-0.8777$ & $0.7 \mid 26 \pm 0.03807$ & $0.6355-0.7897$ & 0.132 \\
\hline$P$-value $\mathrm{a}^{\mathrm{a}}$ & 0.718 & & 0.245 & & 0.027 & & \\
\hline
\end{tabular}

Note: ${ }^{\text {aKruskal-Wallis test. }}$

Abbreviations: $\mathrm{Cl}$, confidence interval; SD, standard deviation. 
Table 4 Utility values by type of glaucoma surgery

\begin{tabular}{|c|c|c|c|}
\hline \multicolumn{4}{|l|}{ Utility values } \\
\hline Type of surgery & Mean & $\begin{array}{l}\text { Standard } \\
\text { deviation }\end{array}$ & $P$-value ${ }^{a}$ \\
\hline Laser surgery & 0.8573 & 0.09693 & 0.402 \\
\hline Trabeculectomy & 0.7830 & 0.04232 & \\
\hline Non-penetrating deep sclerectomy & 0.7855 & 0.02190 & \\
\hline Glaucoma drainage implant & 0.8290 & 0.03537 & \\
\hline
\end{tabular}

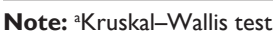

analogs (bimatoprost: 0.7533 ; latanoprost: 0.8499 ; travoprost: 0.8249; $P=0.097$, Kruskal-Wallis test).

One-hundred and forty-three patients had undergone glaucoma surgery in at least one eye in our study population. The following procedures were present: laser surgery: $6.9 \%$ (10/143); trabeculectomy: $14.7 \%$ (21/143); non-penetrating deep sclerectomy: 69.2\% (99/143); and glaucoma drainage implant (Ahmed): 7.7\% (11/143). Two patients (1.4\%) had been submitted for both laser peripheral iridotomy and trabeculectomy. Table 4 shows the mean utility values for each glaucoma surgical technique.

\section{Discussion}

Our findings suggest that the type of glaucoma therapy does not interfere with utility values. Glaucoma severity was the most important variable affecting the utility values in this population.

One of the major drivers of a patient-reported QOL is visual function (poor visual acuity and advanced visual field loss). ${ }^{2,12,14-17}$ Although the literature shows strong evidence that the visual function in the better eye has a major impact on QOL, some authors have demonstrated that the worse eye can also have an influence on a patient's QOL. ${ }^{14-16}$ Others have also shown that the binocular visual field and its rate of progression can impact the QOL scores. ${ }^{17}$ In our study, we decided to use the better-eye visual function variables because this is the most common method in the literature.

Few studies in the literature have investigated the impact of different treatment approaches on the QoL of patients with glaucoma, using a QoL score as an outcome measure. ${ }^{6,7}$ The most important study on this subject is the CIGTS. ${ }^{6}$ In this clinical trial, patients were randomized to either medical or surgical (trabeculectomy) treatment. They assessed the QoL of participants using three questionnaires, but no measure of utility values was included. QoL in the surgery group was worse than in the medication arm. Our group suggested, in a previous study, that surgery had a negative impact on QoL in earlier stages of glaucoma. We used the 25-item National Eye Institute Visual Functioning Questionnaire (NEI VFQ-25) questionnaire for that analysis. ${ }^{7}$
To our knowledge, no previous study has specifically evaluated the impact of different treatment options on the utility values in a glaucoma population. The only study that we have found in the literature was from India, and the authors only indirectly evaluated the impact of medications on the utility values. ${ }^{18}$ Gupta et al ascertained utility values for a population from India and found that they were not correlated with the number of medications in use by the patients. The only factor that correlated well with the utility values in this study was the visual function in the better eye. ${ }^{18}$ This finding is consistent with our study results, and also with many others in the literature. . $^{12,18-20}$

In a first analysis, we found that mean utility values in groups 1 (exclusive medical therapy), 2 (exclusive surgical therapy), and 3 (mixed surgical and medical therapy) were statistically different $(P=0.017)$. However, when we stratified our population by glaucoma stage, this difference disappeared ( $P=0.641$ for early glaucoma; $P=0.648$ for moderate glaucoma; $P=0.132$ for advanced glaucoma), demonstrating that glaucoma severity was the main variable responsible for the difference. So our results suggest that glaucoma surgery does not affect the utility values in a glaucoma population.

We also tested whether the type of glaucoma surgery produced any impact on the utility values. No differences were found among the glaucoma surgeries used in this population (trabeculectomy, laser surgery, non-penetrating deep sclerectomy, or glaucoma drainage device).

Our group has demonstrated that not all prostaglandin analogs have the same impact on patients' QoL. In this previous study, bimatoprost was associated with a worse NEI VFQ-25 score even after being controlled by glaucoma severity and visual acuity. ${ }^{21}$ In the present study, the type of prostaglandin analog in use by the patients did not influence the utility values.

We decided to use the TTO method for this study. In a previous study, we noticed that our population had some difficulties in understanding the standard gamble test. ${ }^{12}$ Bozzani et al also found that TTO was more sensitive than the EQ-5D and SF-6D for capturing changes in vision and visual functioning associated with glaucoma. ${ }^{22}$

Our study suffers from some limitations. In the utility value comparisons among different surgical techniques, some groups had small sample sizes, which could have affected our results. Our surgical sample was biased toward a non-penetrating procedure (almost $70 \%$ of our sample), which is known to have fewer complications than traditional trabeculectomy. This can, in theory, have an impact on the perception of QoL by the patient. More investigation on this subject is needed to validate our findings. Our study was a cross-sectional evaluation and a definitive result should be confirmed in a prospective trial. 
Another point that should be considered about our study is that we investigated the impact of different treatment modalities on the utility values, a generic QOL metric. If a more specific metric (an ophthalmology-specific or a glaucoma-specific instrument), which would be more sensitive to small changes in vision-related symptoms, were used, the differences among the treatments could appear. It is also important to emphasize that TTO is a subjective method that can be affected by patients' beliefs and backgrounds.

Age, sex, level of education, and ocular and systemic comorbidities were potential confounding variables for QoL assessment. However, they did not influence our results, as there were no significant differences in these variables among the studied groups.

The economic and financial burdens of glaucoma are enormous, and health economics studies are important and necessary to help clinicians, health managers, and policymakers to better decide which treatment strategy is best applied in a specific situation. ${ }^{1}$ Therefore, cost-utility evaluations are most useful. ${ }^{8,10,11}$ Determining utility values and their drivers for a glaucoma population is very important and can help future health economics and outcomes research. The Brazilian Ministry of Health has encouraged more cost-utility studies in order to improve the efficiency of the Brazilian public health system (SUS). ${ }^{23}$

\section{Conclusion}

Our findings suggest that the type of glaucoma therapy seems to have no impact on the utility values in a glaucoma population.

\section{Disclosure}

The authors report no conflicts of interest in this work.

\section{References}

1. Varma R, Lee PP, Goldberg I, Kotak S. An assessment of the health and economic burdens of glaucoma. Am J Ophthalmol. 2011;152(4): 515-522.

2. McKean-Cowdin R, Varma R, Wu J, Hays RD, Azen SP; Los Angeles Latino Eye Study Group. Severity of visual field loss and health-related quality of life. Am J Ophthalmol. 2007;143(6):1013-1023.

Clinical Ophthalmology

\section{Publish your work in this journal}

Clinical Ophthalmology is an international, peer-reviewed journal covering all subspecialties within ophthalmology. Key topics include: Optometry; Visual science; Pharmacology and drug therapy in eye diseases; Basic Sciences; Primary and Secondary eye care; Patient Safety and Quality of Care Improvements. This journal is indexed on Submit your manuscript here: http://www.dovepress.com/clinical-ophthalmology-journal
3. Friedman DS, Freeman E, Munoz B, Jampel HD, West SK. Glaucoma and mobility performance: the Salisbury Eye evaluation project. Ophthalmology. 2007;114(12):2232-2237.

4. Ramulu P. Glaucoma and disability: which tasks are affected, and at what stage of disease? Curr Opin Ophthalmol. 2009;20(2):92-98.

5. European Glaucoma Society. Terminology and Guidelines for Glaucoma. 2nd ed. Savona: Editrice Dogma; 2003.

6. Feiner L, Piltz-Seymour JR; Collaborative Initial Glaucoma Treatment Study. Collaborative Initial Glaucoma Treatment Study: a summary of results to date. Curr Opin Ophthalmol. 2003;14:106-111.

7. Guedes RA, Guedes VM, Freitas SM, Chaoubah A. Quality of life of medically versus surgically treated glaucoma patients. J Glaucoma. 2013;22(5):369-373.

8. Kymes SM. An introduction to decision analysis in the economic evaluation of the prevention and treatment of vision-related diseases. Ophthalmic Epidemiol. 2008;15(2):76-83.

9. Tsevat J. What do utilities measure? Med Care. 2000;38(9 Suppl): II160-II164.

10. Brown M. Utility analysis tells all. Br J Ophthalmol. 2005;89:1233.

11. Brown GC, Brown MM, Sharma S, et al. Value-based medicine and ophthalmology: an appraisal of cost-utility analyses. Trans Am Ophthalmol Soc. 2004;102:177-188.

12. Paletta Guedes RA, Paletta Guedes VM, Freitas SM, Chaoubah A. Utility values for glaucoma in Brazil and their correlation with visual function. Clin Ophthalmol. 2014;8:529-535.

13. Hodapp E, Parrish RK II, Anderson DR. Clinical Decisions in Glaucoma. St Louis: Mosby; 1993.

14. Chan EW, Chiang PP, Wong TY, et al. Impact of glaucoma severity and laterality on vision-specific functioning: the Singapore Malay eye study. Invest Ophthalmol Vis Sci. 2013;54(2):1169-1175.

15. Hirneiß C, Reznicek L, Vogel M, Pesudovs K. The impact of structural and functional parameters in glaucoma patients on patient-reported visual functioning. PLoS One. 2013;8(12):e80757.

16. Hirneiss $\mathrm{C}$. The impact of a better-seeing eye and a worse-seeing eye on vision-related quality of life. Clin Ophthalmol. 2014;8:1703-1709.

17. Lisboa R, Chun YS, Zangwill LM, et al. Association between rates of binocular visual field loss and vision-related quality of life in patients with glaucoma. JAMA Ophthalmol. 2013;131(4):486-494.

18. Gupta V, Srinivasan G, Mei SS, Gazzard G, Sihota R, Kapoor KS. Utility values among glaucoma patients: an impact on the quality of life. Br J Ophthalmol. 2005;89(10):1241-1244.

19. Jampel HD. Glaucoma patients' assessment of their visual function and quality of life. Trans Am Ophthalmol Soc. 2001;99:301-317.

20. Saw SM, Gazzard G, Au Eong KG, Oen F, Seah S. Utility values in Singapore Chinese adults with primary open-angle and primary angleclosure glaucoma. J Glaucoma. 2005;14(6):455-462.

21. Guedes RA, Guedes VM, Freitas SM, Chaoubah A. Quality of life of glaucoma patients under medical therapy with different prostaglandins. Clin Ophthalmol. 2012;6:1749-1753.

22. Bozzani FM, Alavi Y, Jofre-Bonet M, Kuper H. A comparison of the sensitivity of EQ-5D, SF-6D and TTO utility values to changes in vision and perceived visual function in patients with primary open-angle glaucoma. BMC Ophthalmol. 2012;12:43.

23. Methodological Guidelines: Health Technology Assessment Appraisals. Brazil: Ministry of Health of Brazil; 2009.
PubMed Central and CAS, and is the official journal of The Society of Clinical Ophthalmology (SCO). The manuscript management system is completely online and includes a very quick and fair peer-review system, which is all easy to use. Visit http://www.dovepress.com/ testimonials.php to read real quotes from published authors. 